\title{
Pilot evaluation of the HELENA (Healthy Lifestyle in Europe by Nutrition in Adolescence) Food-O-Meter, a computer-tailored nutrition advice for adolescents: a study in six European cities
}

\author{
Lea Maes ${ }^{1}$ * , Tina Louisa Cook ${ }^{2}$, Charlene Ottovaere $^{1}$, Christophe Matthijs ${ }^{1}$, \\ Luis A Moreno ${ }^{3}$, Mathilde Kersting ${ }^{4}$, Alina Papadaki ${ }^{5}$, Yannis Manios ${ }^{2}$, \\ Sabine Dietrich ${ }^{6}$, Lena Hallström ${ }^{7}$, Leen Haerens ${ }^{8,9}$, Ilse De Bourdeaudhuij ${ }^{8}$ and \\ Carine Vereecken ${ }^{1,9}$ on behalf of the HELENA Study Groupt \\ 'Department of Public Health, Ghent University, Watersportlaan 2, 9000 Ghent, Belgium: ${ }^{2}$ Department of \\ Nutrition and Dietetics, Harokopio University, Kallithea, Athens, Greece: ${ }^{3}$ Growth, Exercise, Nutrition and \\ Development' (GENUD) Research Group, EU Ciencias de la Salud, Universidad de Zaragoza, Zaragoza, Spain: \\ ${ }^{4}$ Research Institute of Child Nutrition, Rheinische Friedrich-Wilhelms-Universität Bonn, Dortmund, Germany: \\ ${ }^{5}$ Department of Social Medicine, University of Crete, Heraklion, Crete, Greece: ${ }^{6}$ Department of Pediatrics, \\ Clinical Nutrition and Prevention, Medical University of Vienna, Vienna, Austria: ${ }^{7}$ Unit for Preventive Nutrition, \\ Department of Biosciences and Nutrition, Karoliǹska Institute, Huddinge, Sweden: ${ }^{8}$ Department of Movement \\ and Sport Sciences, Ghent University, Ghent, Belgium: ${ }^{9}$ Research Foundation-Flanders, Belgium
}

Submitted 21 January 2010: Accepted 23 November 2010: First published online 31 January 2011

\begin{abstract}
Objective: To investigate the feasibility and impact of the Food-O-Meter, an Internet-based computer-tailored nutrition intervention in adolescents.

Design: Participants in the intervention condition received the computer-tailored advice at baseline and at 1 month, those in the control condition received standardised advice. Effects were evaluated at 1 month ( $n$ 621) and at 3 months ( $n$ 558) using multi-level modelling.

Setting: Secondary schools in six European cities. Adolescents accessed the intervention in the school computer room under the supervision of teachers.

Subjects: Classes with students aged 12-17 years in the schools participating in the HELENA (Healthy Lifestyle in Europe by Nutrition in Adolescence) cross-sectional study were randomised into intervention and control schools.

Results: In most participating centres the intervention was feasible and generally well appreciated, especially by girls. Technical problems and lack of motivation of the teachers hindered implementation in some centres. Overweight adolescents had higher scores for reading and using the advice than normal weight adolescents. After 1 month adolescents receiving the standardised advice reported an increase in fat intake, while fat intake in the intervention condition was stable $(F=4 \cdot 82, P<0 \cdot 05)$. After 3 months, there was a trend in the total group for an intervention effect of the tailored advice on fat intake $(F=2 \cdot 80, P<0 \cdot 10)$. In the overweight group there was a clear positive effect $(F=5 \cdot 76, P<0 \cdot 05)$.

Conclusions: The Food-O-Meter should be developed further. The results were modest but clear for percentage energy from fat, specifically in the overweight group. Adaptations based on new research are needed to enhance the reliability and effectiveness of the intervention.
\end{abstract}

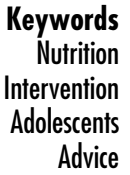

Keywords Intervention Advice
Previous studies have shown that children and adolescents have unfavourable eating habits ${ }^{(1-5)}$. Energy and fat intakes are far above recommendations, fruit and vegetable consumption is less than desirable and consumption of snacks and soft drinks is too high ${ }^{(4,6)}$. Unhealthy dietary patterns in adolescence can negatively affect growth

$\uparrow$ See Appendix for members of the HELENA Study Group. and development ${ }^{(7)}$ and when carried into adulthood may result in chronic diseases in later life, such as diabetes, hypertension, cancer and $\mathrm{CVD}^{(8-12)}$.

The school environment can serve as an ideal place for the development of interventions aiming at assisting children and adolescents to adopt healthy behaviours ${ }^{(13,14)}$. Results from previous school-based interventions have revealed favourable but modest changes in eating behaviours, 
BMI and lipid profile ${ }^{(15-19)}$. However, the cost of such interventions is very high. Computer-tailored interventions have emerged as a new and cost-effective type of health promotion programme because they enable personalisation of health education without the high costs of interpersonal counselling ${ }^{(20)}$. Such interventions provide individualised feedback about participants' health behaviours and personalised suggestions on how to achieve the desired behaviours ${ }^{(20-22)}$. Computer-tailored interventions provide personalised feedback on individuals' deviation from recommendations, helping them to realise the gap between current and desired dietary behaviours ${ }^{(23)}$. In addition, their applicability in electronic non-print media enables wide distribution with relatively little cost ${ }^{(24)}$.

To date, only a few computer-tailored interventions have tried to target eating behaviours in adolescents. Haerens et al $^{(25)}$ evaluated the effects of a middle-school healthy eating intervention combining environmental changes and computer-tailored feedback. The intervention was effective in reducing fat intake in girls but not in boys. Frenn et al. ${ }^{(26)}$ examined the effectiveness of an Internet-video-delivered intervention to reduce dietary fat intake among low-income adolescents and found that those who completed more than half the sessions decreased the percentage of energy from fat. Casazza and Ciccazzo $^{(27)}$ showed that students receiving computerbased education decreased their self-reported fat intake compared with those receiving traditional education.

All three interventions focused on one or a few food components ${ }^{(25-27)}$, e.g. fat and fibre intake, fruit and vegetable consumption and soft drinks. However, it has been argued that focusing on multiple dietary behaviours simultaneously may be better than addressing one nutrient component at a time ${ }^{(28,29)}$. Therefore the aims of the present study were: (i) to investigate the feasibility of implementing an Internet-based tailored intervention addressing several aspects of the eating habits of adolescents in European cities; (ii) to assess the acceptability of this intervention for schools and students in six European cities; and (iii) to explore the effects of the intervention on the nutrient intakes of adolescents.

\section{Methods}

\section{Study protocol and participants}

Data are part of the Healthy Lifestyle in Europe by Nutrition in Adolescence (HELENA) project. The HELENA project is a European Union-funded research project aimed at obtaining reliable and comparable data on a representative sample of European adolescents concerning nutrition, physical activity and obesity ${ }^{(30,31)}$. The second aim is the development and evaluation of a computer-tailored intervention to promote physical activity and healthy eating. The physical activity component - the Activ-O-Meter - is a Flemish intervention that was adapted for use in an international context; the evaluation is reported elsewhere ${ }^{(32)}$. The present study focuses on the feasibility, appreciation and effectiveness of the Food-O-Meter. For this a drop-out analysis is performed, the appreciation of the advice is investigated with a questionnaire and the intervention effects on the adolescents' nutrient intakes are explored.

\section{Intervention (the Food-O-Meter)}

The Food-O-Meter is part of the HELENA lifestyle intervention (LSEI). The LSEI consists of two components: a physical activity component (the Activ-O-Meter) and a nutrition component (the Food-O-Meter). All intervention schools had to implement the two components and all implemented the Activ-O-Meter first. The development of the Food-O-Meter was based on the procedure of developing computer-based interventions described by Brug et al. ${ }^{(33)}$.

The Food-O-Meter consists of: (i) a validated FFQ for measuring the dietary intake of adolescents; (ii) a food composition database; and (iii) a decision tree for generating individualised advice for enhancing the dietary intakes of fibre, vitamin $\mathrm{C}, \mathrm{Ca}, \mathrm{Fe}$ and fat and for beverages. The intervention starts with an introductory page giving information on the aim of the intervention, questions on age, gender, height and weight, and screening questions for eating disorders. Adolescents identified as at risk for eating disorders and those following a prescribed diet could not continue to fill in the questionnaires and got standard advice on healthy eating.

Intakes of energy and the target nutrients (fat, fibre, $\mathrm{Ca}$, vitamin $\mathrm{C}$ and $\mathrm{Fe}$ ) were assessed with an FFQ. The FFQ was developed based on the validated computerised FFQ for fat intake developed in Belgium ${ }^{(34)}$, further extended and adapted to measure the intake of the target nutrients. In total, 137 items (food groups e.g. fresh fruit; individual food items e.g. white bread) were identified as contributing substantially to the overall intake of these components. Each country could include country-specific examples and portion sizes for each food item ${ }^{(35)}$. A reproducibility and relative validity study in forty-eight Flemish adolescents showed good reproducibility correlations $(0 \cdot 46-0 \cdot 90)$. Comparison against four $24 \mathrm{~h}$ recalls in the same adolescents showed a relatively small overestimation in seven food groups resulting in an overestimation of energy, Fe, fibre and vitamin C and an underestimation of percentage of energy from fat ${ }^{(36)}$. As these results were based on a rather small Flemish convenience sample, over- and underestimations were not taken into account for generating the individual feedback in the current phase. There were no reproducibility and validity studies in the other study centres.

For calculating nutrient intakes, a food composition database was built with a total of 137 items mainly from the German Federal Food Code (BLS) ${ }^{(37)}$ and supplemented with the Dutch $^{(38)}$ and the Belgian ${ }^{(39)}$ food composition tables. 


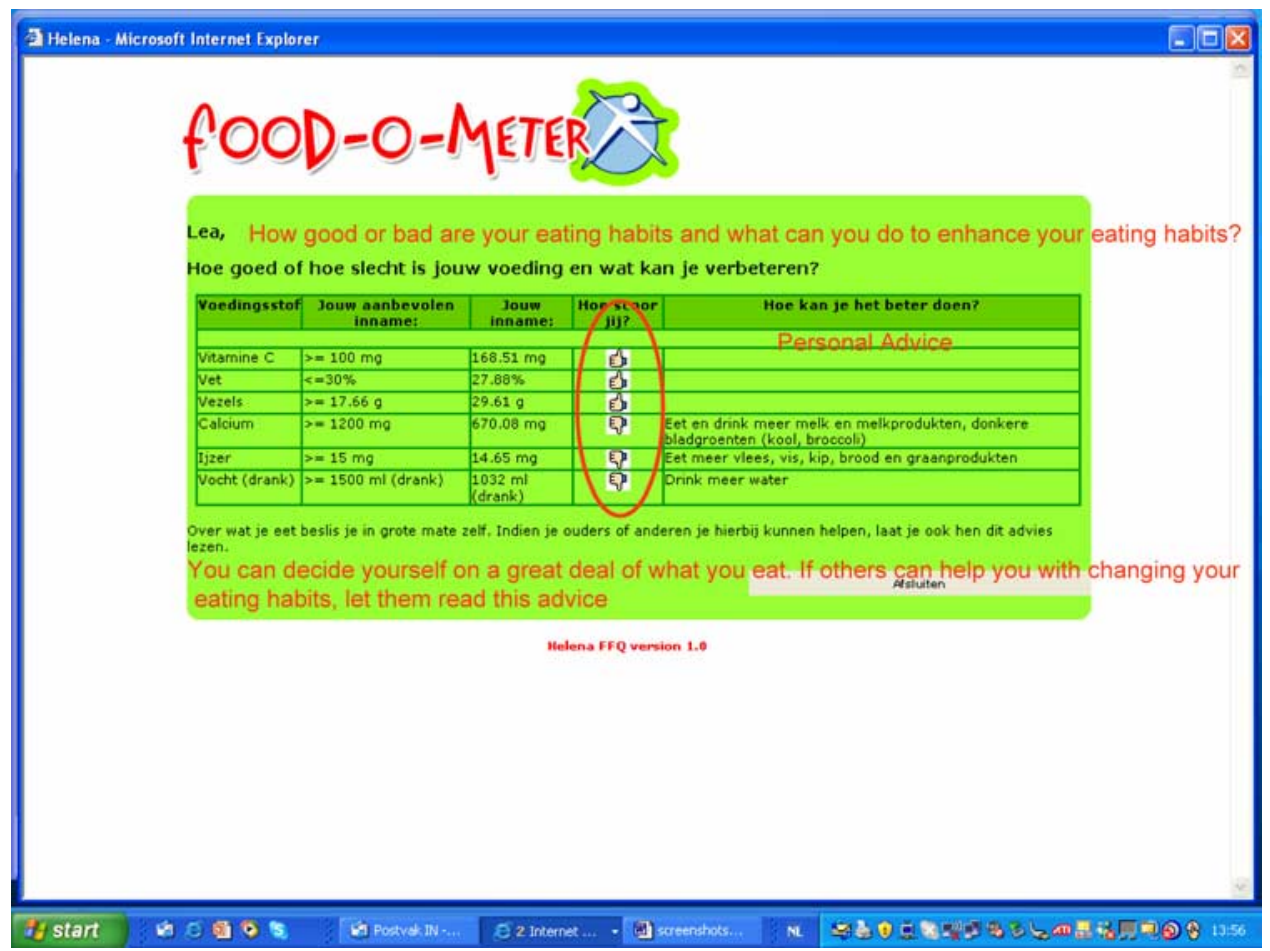

Fig. 1 Example of advice given to the adolescents

The researchers and teachers guided the students through the computer-tailored program. The tailored advice was generated by a decision tree comparing the reported intake for the target nutrients with the (Belgian) recommended intake. The feedback was given in a short tabular form, including the recommended intake, the respondent's actual intake and a symbol indicating if this was 'OK' or not (Fig. 1). Furthermore, for the 'not OK' nutrients recommendations were generated on the food level (e.g. for fibre: eat more fruit, vegetables). Below the table a sentence was added on the importance of handing the results to others who could help them improve their diet. The advice could be mailed to their personal email address or be printed.

The nutrient intakes assessed with the FFQ were also used for evaluating the effect of the intervention on the students' nutrient intake.

\section{Feasibility questionnaire}

Feasibility for the teachers was measured by the drop out of classes from the study.

Evaluation of the appreciation of the intervention by the adolescents was based on existing questionnaires previously used in adults ${ }^{(40)}$. Twelve items evaluated the advice and one item measured the intended use of the advice. Answers were rated on a 5-point scale from 'totally disagree' to 'totally agree'.

\section{Participating schools}

The schools participating in the HELENA cross-sectional study were randomised into 'intervention schools' and 'control schools'. More detail on the selection of the schools for the HELENA Study is provided in Moreno et $a l^{(41)}$. The random assignment to one of the conditions was done by the researchers by simple randomisation and could not be chosen by the school. The six study centres - Vienna, Ghent, Heraklion, Dortmund, Athens and Stockholm - were asked to recruit at least 200 adolescents of the cross-sectional study within these schools to participate in the intervention study (100 adolescents in the control condition and 100 in the intervention condition). This resulted in a quasi-experimental design as schools and classes and not participants were randomised within the conditions.

\section{Design of the evaluation study}

The evaluation study consisted of short-term (1-month) and medium-term (3-month) impact evaluations. The intervention was delivered in the classes in all schools by instructed teachers. At baseline, researchers were present to detect and help to solve possible ICT (information and communications technology) problems. Participants in the intervention condition received the computer-tailored advice at baseline (T1) and at 1 month (T2). Participants in the control condition received generic standard advice in text format covering similar topics as included in the tailored advice at baseline (T1) and at 1 month (T2). At baseline, a separate written acceptability questionnaire was filled in by all students. The students completed the online computer-tailored program and immediately thereafter the acceptability questionnaire during school hours. 
As the intervention was considered to be part of the regular curriculum, every student present in the classroom participated in the intervention. At T3 all students got tailored advice.

The baseline measurements (T1) were executed in most study centres during February and March 2007. The short-term post-measurements were conducted 1 month later (T2) and the medium-term post-measurements at 3 months post-baseline (T3). A few classes, included in the data, completed the intervention after this period.

\section{Statistical analysis}

The frequencies of adolescents participating in the FoodO-Meter are described by country, condition, gender and age category.

Three-level (pupil-school-study centre) linear-mixed models with random intercepts at the study centre and school level were used to explore differences between the appreciation of the standard and tailored advice, controlling for gender, age, dieting and weight status. To investigate sociodemographic differences (gender, age, dieting and weight status) in appreciation, separate linear-mixed model analyses were run for intervention and control groups, controlling for the other sociodemographic variables.

For analysing the intervention effects only those participants finalising all items of the questionnaire and with energy intake between 2510 and $25100 \mathrm{~kJ}$ (600 and $6000 \mathrm{kcal})$ were included in the analyses.

Linear-mixed models on post-intervention measures of nutrient intake (T2), with condition as between-subject factors, were used to explore short-term intervention effects. Gender and gender-by-condition interaction effects, and weight status at baseline and weight status at baseline-by-condition interaction effects, were entered as factors in the model. Where significant interaction effects were found separate analyses were performed. Analyses were adjusted for baseline values of nutrient intake (T1) and age. The same analyses were repeated to assess medium-term intervention effects by entering nutrient intake at T3 as the dependent variable in the model.

The results from models with main effects only are presented in the tables. $P<0.05$ was considered as significant, $P \leq 0 \cdot 10$ as indicating trend. All analyses were performed using the SPSS statistical software package version $15 \cdot 0$ (SPSS Inc., Chicago, IL, USA).

\section{Results}

\section{Participation and feasibility}

Table 1 gives an overview of participating adolescents. In total, 1298 adolescents were enrolled in the study at baseline, spread over the six study centres. As inclusion differed by study centre and condition, more students were included in the intervention schools. Drop out did not differ by condition, but differed greatly by study centre.

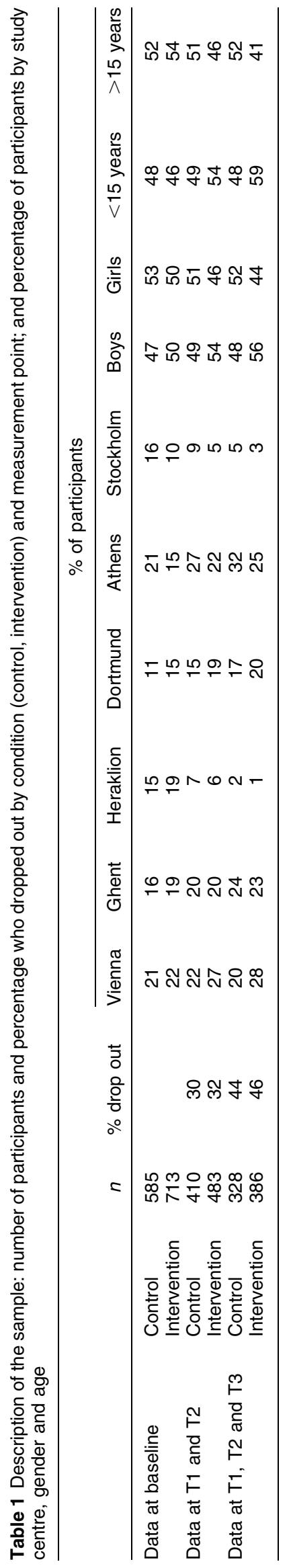


Table 2 Estimated marginal means by condition and significance of the difference, using mixed models controlling for gender, age, weight status and being on a diet

\begin{tabular}{|c|c|c|c|c|c|c|c|}
\hline & \multicolumn{3}{|c|}{ Control } & \multicolumn{3}{|c|}{ Intervention } & \multirow[b]{2}{*}{$P$} \\
\hline & Mean & SE & $n$ & Mean & SE & $n$ & \\
\hline advice $=$ believable & $3 \cdot 62$ & 0.09 & 472 & $3 \cdot 61$ & 0.09 & 556 & 0.989 \\
\hline advice $=$ relevant & $3 \cdot 91$ & $0 \cdot 10$ & 470 & 3.87 & $0 \cdot 10$ & 559 & 0.638 \\
\hline advice $=$ interesting & $3 \cdot 80$ & $0 \cdot 13$ & 470 & $3 \cdot 84$ & $0 \cdot 13$ & 559 & 0.615 \\
\hline advice $=$ logical & $4 \cdot 04$ & $0 \cdot 11$ & 471 & 3.98 & $0 \cdot 10$ & 561 & 0.413 \\
\hline advice $=$ understandable & $3 \cdot 87$ & 0.08 & 471 & $3 \cdot 78$ & 0.08 & 554 & $0 \cdot 198$ \\
\hline advice $=$ well formulated & $3 \cdot 82$ & 0.09 & 471 & $3 \cdot 83$ & 0.09 & 560 & 0.869 \\
\hline advice $=$ complete & $3 \cdot 87$ & $0 \cdot 11$ & 469 & $3 \cdot 78$ & $0 \cdot 10$ & 561 & 0.237 \\
\hline advice $=$ too long & $3 \cdot 44$ & $0 \cdot 11$ & 465 & $3 \cdot 11$ & $0 \cdot 11$ & 562 & 0.002 \\
\hline advice $=$ personal & $3 \cdot 16$ & $0 \cdot 10$ & 470 & $3 \cdot 40$ & $0 \cdot 10$ & 556 & $<0.001$ \\
\hline advice $=$ correct & $3 \cdot 72$ & 0.11 & 471 & $3 \cdot 73$ & $0 \cdot 11$ & 553 & 0.978 \\
\hline read the advice & $3 \cdot 98$ & $0 \cdot 13$ & 465 & $4 \cdot 10$ & $0 \cdot 12$ & 559 & $0 \cdot 194$ \\
\hline will use the advice & $3 \cdot 52$ & 0.13 & 467 & 3.62 & $0 \cdot 13$ & 559 & $0 \cdot 188$ \\
\hline the advice will help me to eat healthier & $3 \cdot 56$ & $0 \cdot 17$ & 470 & $3 \cdot 65$ & $0 \cdot 17$ & 558 & 0.346 \\
\hline the advice does not contain enough info & $2 \cdot 30$ & $0 \cdot 12$ & 472 & $2 \cdot 51$ & $0 \cdot 12$ & 555 & 0.008 \\
\hline
\end{tabular}

Bold font indicates significant $P$ values.

At baseline (T1) somewhat more girls were included in the study in the control schools. For the analysis at T3 somewhat more girls were included in the control schools and more boys were included in the intervention schools. Older ( $>15$ years) adolescents were greater in number at baseline in the control schools and intervention schools. At T3 there was lower number of older adolescents in the intervention schools.

\section{Adolescents' acceptability of the advice}

Table 2 gives an overview of the answers on questions concerning the advice received. Overall, the students in the intervention and control conditions were positive about the advice received, as indicated by scores $>3$ (scale 1-5). Highest mean scores were obtained in the control condition for the logical structure of the advice and in the intervention condition for having read the advice. Lowest scores in both conditions were for the amount of information given in the advice. The scores between the conditions differed significantly for the length of the advice (in the control condition the score for 'too long' was higher); for the personal aspect of the advice (the score was higher in the intervention schools); and for the amount of information given (the score was higher in the intervention schools for 'advice does not contain enough info').

Table 3 gives an overview of the sociodemographic differences in appreciation by condition. In the control condition as well as the intervention condition, boys appreciated the advice received less than girls for most items. The overweight adolescents in the control condition had a higher score on the items 'the advice is interesting' and 'the advice will help me to eat healthier' than normal weight adolescents. In the intervention condition, overweight adolescents had a higher score for 'the advice is well formulated', for 'having read the advice' and for 'I will use the advice' compared with normal weight adolescents.
Those adolescents following a special diet in the intervention condition had higher scores for the items 'the advice is logical', 'the advice will help me to eat healthier' and 'the advice does not contain enough info' $v$. those not following a special diet. There were no significant differences on the items for these adolescents in the control condition. In no condition were there significant differences in appreciation scores for younger $v$. older or for underweight $v$. normal weight adolescents.

\section{Intervention effects at the nutrient level}

Table 4 shows the results of the analyses for the total sample at T1 (baseline), T2 (1 month) and T3 (3 months), investigating the effects of the computer-tailored intervention compared with the standard feedback after 1 month and after 3 months.

At T2 a significant interaction effect of weight status at baseline by condition was found for vitamin C. Separate analyses of normal weight and overweight adolescents resulted in a significant difference only for the overweight group. An increase in vitamin $\mathrm{C}$ was found for students in the intervention condition, mean intake from 33.22 (sD $17 \cdot 42) \mathrm{mg} / 4184 \mathrm{~kJ}$ to $38 \cdot 26(\mathrm{sD} 21 \cdot 26) \mathrm{mg} / 4184 \mathrm{~kJ}$ $(4184 \mathrm{~kJ}=1000 \mathrm{kcal})$, and a decrease in vitamin $\mathrm{C}$ for students in the control condition, mean intake from $34 \cdot 22$ (SD $18.54) \mathrm{mg} / 4184 \mathrm{~kJ}$ to $31 \cdot 22$ (sD $16 \cdot 81) \mathrm{mg} / 4184 \mathrm{~kJ}(F=4.57$, $P=0 \cdot 03)$. No interaction effects were found for gender.

Follow-up analysis of the total sample ( $n$ 621) found a significant main effect for percentage energy from fat $(F=4 \cdot 82, P=0 \cdot 029)$. In the control group the percentage energy from fat increased at T2 and in the intervention group no change in fat intake was recorded.

At T3 ( $n$ 558) there was a modest intervention effect for percentage energy from fat, showing a smaller increase in the intervention condition $(F=2 \cdot 80, P=0 \cdot 097)$. Moreover, there was a significant interaction effect for weight status at baseline by condition for percentage energy from fat and for 
Table 3 Sociodemographic differences in appreciation by condition: parameter estimates of linear mixed models for gender, age, dieting and weight statust controlling for each other and significance of the parametersł

\begin{tabular}{|c|c|c|c|c|c|c|c|c|c|c|c|c|c|c|c|}
\hline & \multicolumn{3}{|c|}{ Boy } & \multicolumn{3}{|c|}{15 years or older } & \multicolumn{3}{|c|}{ Special diet } & \multicolumn{3}{|c|}{ Underweight } & \multicolumn{3}{|c|}{ Overweight } \\
\hline & Estimate & SE & $P$ & Estimate & SE & $P$ & Estimate & SE & $P$ & Estimate & SE & $P$ & Estimate & $\mathrm{SE}$ & $P$ \\
\hline \multicolumn{16}{|l|}{ Control } \\
\hline advice $=$ believable & $-0 \cdot 21$ & 0.09 & 0.026 & -0.15 & $0 \cdot 10$ & $0 \cdot 127$ & -0.07 & $0 \cdot 15$ & 0.653 & $-0 \cdot 13$ & $0 \cdot 18$ & 0.480 & -0.11 & $0 \cdot 12$ & 0.365 \\
\hline advice $=$ relevant & $-0 \cdot 28$ & 0.09 & 0.003 & -0.05 & $0 \cdot 10$ & 0.630 & 0.00 & $0 \cdot 14$ & 0.983 & 0.04 & $0 \cdot 17$ & 0.814 & $0 \cdot 11$ & $0 \cdot 11$ & 0.322 \\
\hline advice $=$ interesting & -0.23 & 0.09 & 0.015 & 0.00 & $0 \cdot 11$ & 0.969 & -0.20 & $0 \cdot 15$ & 0.182 & 0.05 & $0 \cdot 18$ & 0.767 & 0.23 & $0 \cdot 12$ & 0.048 \\
\hline advice $=$ logical & $-0 \cdot 21$ & 0.09 & 0.016 & 0.08 & $0 \cdot 10$ & 0.434 & $0 \cdot 22$ & $0 \cdot 13$ & 0.091 & 0.07 & $0 \cdot 16$ & 0.650 & 0.04 & $0 \cdot 11$ & 0.688 \\
\hline advice $=$ understandable & $-0 \cdot 11$ & 0.09 & 0.205 & 0.01 & 0.09 & 0.898 & $0 \cdot 14$ & $0 \cdot 14$ & 0.329 & $0 \cdot 15$ & $0 \cdot 17$ & 0.360 & $0 \cdot 16$ & $0 \cdot 11$ & $0 \cdot 136$ \\
\hline advice $=$ well formulated & $-0 \cdot 17$ & 0.09 & 0.062 & -0.08 & $0 \cdot 10$ & 0.432 & $0 \cdot 15$ & $0 \cdot 14$ & 0.290 & $0 \cdot 23$ & $0 \cdot 17$ & $0 \cdot 170$ & 0.22 & $0 \cdot 11$ & 0.052 \\
\hline advice $=$ complete & -0.04 & 0.09 & 0.672 & $-0 \cdot 12$ & $0 \cdot 10$ & 0.253 & $0 \cdot 20$ & $0 \cdot 14$ & $0 \cdot 170$ & -0.05 & $0 \cdot 18$ & 0.763 & 0.02 & $0 \cdot 11$ & 0.854 \\
\hline advice $=$ too long & 0.24 & $0 \cdot 12$ & 0.042 & -0.19 & $0 \cdot 12$ & $0 \cdot 111$ & $-0 \cdot 17$ & $0 \cdot 19$ & 0.383 & -0.04 & 0.23 & 0.859 & $-0 \cdot 15$ & $0 \cdot 15$ & $0 \cdot 320$ \\
\hline advice $=$ personal & 0.05 & $0 \cdot 10$ & 0.601 & $-0 \cdot 18$ & $0 \cdot 10$ & 0.086 & 0.06 & $0 \cdot 17$ & 0.745 & 0.05 & $0 \cdot 21$ & 0.824 & $0 \cdot 24$ & $0 \cdot 13$ & 0.075 \\
\hline advice $=$ correct & $-0 \cdot 19$ & $0 \cdot 10$ & 0.049 & -0.04 & $0 \cdot 11$ & 0.702 & 0.07 & $0 \cdot 15$ & 0.639 & 0.01 & $0 \cdot 19$ & 0.950 & 0.03 & $0 \cdot 12$ & 0.806 \\
\hline read the advice & -0.39 & $0 \cdot 11$ & $<0.001$ & -0.06 & $0 \cdot 13$ & 0.612 & 0.06 & $0 \cdot 17$ & $0 \cdot 737$ & -0.06 & $0 \cdot 21$ & 0.771 & 0.00 & $0 \cdot 14$ & 0.992 \\
\hline will use the advice & -0.31 & $0 \cdot 10$ & 0.002 & $-0 \cdot 21$ & $0 \cdot 11$ & 0.058 & $0 \cdot 13$ & $0 \cdot 16$ & 0.393 & $-0 \cdot 11$ & $0 \cdot 19$ & 0.568 & 0.22 & $0 \cdot 13$ & 0.082 \\
\hline the advice will help me to eat healthier & $-0 \cdot 24$ & $0 \cdot 11$ & 0.032 & $-0 \cdot 13$ & $0 \cdot 12$ & 0.285 & $-0 \cdot 18$ & $0 \cdot 17$ & 0.289 & $0 \cdot 01$ & $0 \cdot 21$ & 0.944 & 0.31 & $0 \cdot 14$ & 0.027 \\
\hline the advice does not contain enough info & $0 \cdot 15$ & $0 \cdot 11$ & $0 \cdot 170$ & $0 \cdot 13$ & $0 \cdot 12$ & 0.255 & -0.27 & $0 \cdot 17$ & $0 \cdot 113$ & $0 \cdot 14$ & $0 \cdot 21$ & 0.504 & $-0 \cdot 17$ & $0 \cdot 14$ & $0 \cdot 207$ \\
\hline \multicolumn{16}{|l|}{ Intervention } \\
\hline advice $=$ believable & $-0 \cdot 19$ & 0.09 & 0.027 & $0 \cdot 12$ & 0.09 & $0 \cdot 187$ & 0.07 & $0 \cdot 15$ & 0.675 & -0.03 & $0 \cdot 19$ & 0.857 & 0.09 & $0 \cdot 10$ & $0 \cdot 380$ \\
\hline advice $=$ relevant & $-0 \cdot 24$ & 0.08 & 0.004 & 0.03 & 0.09 & 0.703 & $0 \cdot 20$ & $0 \cdot 15$ & $0 \cdot 177$ & -0.07 & $0 \cdot 18$ & 0.691 & $0 \cdot 15$ & $0 \cdot 10$ & $0 \cdot 132$ \\
\hline advice $=$ interesting & $-0 \cdot 21$ & 0.08 & 0.009 & $0 \cdot 12$ & 0.09 & $0 \cdot 175$ & $0 \cdot 11$ & $0 \cdot 14$ & $0 \cdot 450$ & $0 \cdot 17$ & $0 \cdot 17$ & 0.318 & $0 \cdot 13$ & $0 \cdot 10$ & $0 \cdot 169$ \\
\hline advice $=$ logical & $-0 \cdot 12$ & 0.08 & $0 \cdot 140$ & -0.01 & 0.09 & 0.906 & 0.31 & $0 \cdot 14$ & 0.031 & 0.03 & $0 \cdot 17$ & 0.858 & -0.06 & $0 \cdot 10$ & 0.557 \\
\hline advice $=$ understandable & $-0 \cdot 15$ & 0.08 & 0.068 & 0.06 & 0.08 & 0.479 & $0 \cdot 13$ & $0 \cdot 15$ & 0.372 & 0.23 & $0 \cdot 18$ & $0 \cdot 208$ & 0.06 & $0 \cdot 10$ & 0.546 \\
\hline advice $=$ well formulated & $-0 \cdot 11$ & 0.08 & $0 \cdot 163$ & $0 \cdot 13$ & 0.09 & $0 \cdot 123$ & 0.28 & $0 \cdot 15$ & 0.055 & 0.04 & $0 \cdot 18$ & 0.814 & $0 \cdot 21$ & $0 \cdot 10$ & 0.030 \\
\hline advice $=$ complete & $-0 \cdot 11$ & 0.08 & 0.168 & $-0 \cdot 11$ & 0.08 & $0 \cdot 175$ & $0 \cdot 15$ & $0 \cdot 14$ & 0.303 & 0.07 & $0 \cdot 18$ & 0.686 & 0.03 & $0 \cdot 10$ & 0.755 \\
\hline advice $=$ too long & $0 \cdot 20$ & $0 \cdot 11$ & 0.071 & $-0 \cdot 10$ & $0 \cdot 12$ & 0.386 & -0.24 & $0 \cdot 20$ & 0.230 & $-0 \cdot 12$ & 0.24 & 0.611 & -0.05 & $0 \cdot 13$ & $0 \cdot 730$ \\
\hline advice $=$ personal & -0.05 & $0 \cdot 10$ & 0.575 & $0 \cdot 14$ & 0.09 & $0 \cdot 129$ & -0.04 & $0 \cdot 17$ & $0 \cdot 814$ & -0.21 & $0 \cdot 21$ & 0.319 & 0.20 & $0 \cdot 11$ & 0.076 \\
\hline advice $=$ correct & $-0 \cdot 22$ & 0.08 & 0.009 & -0.04 & 0.09 & 0.686 & $-0 \cdot 20$ & $0 \cdot 15$ & 0.177 & $-0 \cdot 17$ & $0 \cdot 18$ & 0.364 & $0 \cdot 15$ & $0 \cdot 10$ & $0 \cdot 127$ \\
\hline read the advice & -0.19 & 0.09 & 0.029 & -0.05 & 0.09 & 0.595 & $0 \cdot 18$ & $0 \cdot 16$ & 0.238 & $0 \cdot 10$ & $0 \cdot 19$ & 0.600 & 0.31 & $0 \cdot 11$ & 0.004 \\
\hline will use the advice & $-0 \cdot 20$ & 0.09 & 0.028 & 0.00 & $0 \cdot 10$ & 0.963 & 0.04 & $0 \cdot 16$ & $0 \cdot 785$ & -0.07 & $0 \cdot 20$ & 0.707 & 0.35 & $0 \cdot 11$ & 0.001 \\
\hline the advice will help $r$ & -0.28 & $0 \cdot 10$ & 0.004 & $-0 \cdot 12$ & $0 \cdot 10$ & $0 \cdot 218$ & 0.36 & $0 \cdot 17$ & 0.029 & $0 \cdot 10$ & $0 \cdot 20$ & 0.635 & $0 \cdot 16$ & $0 \cdot 11$ & $0 \cdot 147$ \\
\hline the advice does not contain enough info & 0.05 & $0 \cdot 11$ & 0.615 & 0.03 & $0 \cdot 11$ & 0.801 & 0.43 & $0 \cdot 19$ & 0.023 & -0.26 & 0.23 & 0.257 & $-0 \cdot 14$ & $0 \cdot 13$ & 0.263 \\
\hline
\end{tabular}

tReference category is girl, younger than 15 years, no special diet and normal weight, respectively.

‡Bold font indicates significant $P$ values. 
Table 4 Mean nutrient intakes at baseline and 1-month and 3-month follow-up for the total population

\begin{tabular}{|c|c|c|c|c|c|c|c|}
\hline \multirow[b]{3}{*}{ Results at 1 -month follow-up } & \multicolumn{7}{|c|}{ Total sample ( $n$ 621) } \\
\hline & \multicolumn{2}{|c|}{ Control (n 240) } & \multicolumn{2}{|c|}{ Intervention ( $n$ 381) } & \multirow[b]{2}{*}{ Condition $F$} & \multirow[b]{2}{*}{$B_{\text {condition }}$} & \multirow[b]{2}{*}{ SE } \\
\hline & Mean & SD & Mean & SD & & & \\
\hline \multicolumn{8}{|l|}{ Fibre (g/4184 kJ) } \\
\hline Baseline & $9 \cdot 47$ & $3 \cdot 24$ & $9 \cdot 21$ & $3 \cdot 24$ & 0.00 & -0.01 & $0 \cdot 263$ \\
\hline 1 month & $9 \cdot 55$ & $3 \cdot 16$ & $9 \cdot 69$ & 3.59 & & & \\
\hline \multicolumn{8}{|l|}{ Vitamin C (mg/4184 kJ) } \\
\hline Baseline & $33 \cdot 05$ & $17 \cdot 10$ & $33 \cdot 60$ & $17 \cdot 78$ & 1.09 & $1 \cdot 33$ & $1 \cdot 28$ \\
\hline 1 month & $33 \cdot 13$ & $16 \cdot 17$ & $34 \cdot 59$ & $18 \cdot 12$ & & & \\
\hline \multicolumn{8}{|l|}{$\mathrm{Ca}(\mathrm{mg} / 4184 \mathrm{~kJ})$} \\
\hline Baseline & $397 \cdot 91$ & $177 \cdot 00$ & $349 \cdot 96$ & $142 \cdot 92$ & $2 \cdot 55$ & $18 \cdot 84$ & $11 \cdot 80$ \\
\hline 1 month & $363 \cdot 17$ & $156 \cdot 09$ & $372 \cdot 56$ & $156 \cdot 78$ & & & \\
\hline \multicolumn{8}{|l|}{$\mathrm{Fe}(\mathrm{mg} / 4184 \mathrm{~kJ})$} \\
\hline Baseline & $6 \cdot 02$ & $1 \cdot 10$ & $6 \cdot 38$ & $1 \cdot 31$ & $2 \cdot 22$ & $0 \cdot 13$ & 0.09 \\
\hline 1 month & $5 \cdot 95$ & 1.06 & $6 \cdot 27$ & $1 \cdot 32$ & & & \\
\hline \multicolumn{8}{|l|}{ Fat (\% of energy) } \\
\hline Baseline & $30 \cdot 54$ & 0.07 & $29 \cdot 50$ & 0.07 & $4 \cdot 82^{*}$ & -0.01 & $0 \cdot 01$ \\
\hline \multirow[t]{3}{*}{1 month } & $31 \cdot 01$ & $0 \cdot 07$ & $29 \cdot 96$ & $0 \cdot 07$ & & & \\
\hline & \multicolumn{7}{|c|}{ Total sample ( $n$ 558) } \\
\hline & \multicolumn{2}{|c|}{ Control (n 250) } & \multicolumn{2}{|c|}{ Intervention (n 308) } & & & \\
\hline Results at 3-month follow-up & Mean & SD & Mean & SD & Condition $F$ & $B_{\text {condition }}$ & SE \\
\hline \multicolumn{8}{|l|}{ Fibre (g/4184 kJ) } \\
\hline Baseline & $9 \cdot 90$ & $3 \cdot 44$ & $9 \cdot 36$ & $3 \cdot 26$ & $0 \cdot 10$ & -0.08 & $0 \cdot 25$ \\
\hline 3 months & $9 \cdot 95$ & $3 \cdot 38$ & $9 \cdot 95$ & $3 \cdot 49$ & & & \\
\hline \multicolumn{8}{|l|}{ Vitamin C (mg/4184 kJ) } \\
\hline Baseline & $35 \cdot 20$ & $18 \cdot 82$ & $34 \cdot 72$ & $20 \cdot 01$ & $0 \cdot 83$ & $-1 \cdot 48$ & $1 \cdot 63$ \\
\hline 3 months & $37 \cdot 77$ & $21 \cdot 28$ & $36 \cdot 93$ & $20 \cdot 43$ & & & \\
\hline \multicolumn{8}{|l|}{ Ca (mg/4184 kJ) } \\
\hline Baseline & $376 \cdot 61$ & $168 \cdot 97$ & $356 \cdot 93$ & $137 \cdot 51$ & $2 \cdot 40$ & $17 \cdot 78$ & $11 \cdot 47$ \\
\hline 3 months & $351 \cdot 86$ & $153 \cdot 91$ & $358 \cdot 48$ & $149 \cdot 17$ & & & \\
\hline \multicolumn{8}{|l|}{$\mathrm{Fe}(\mathrm{mg} / 4184 \mathrm{~kJ})$} \\
\hline Baseline & $6 \cdot 22$ & $1 \cdot 22$ & $6 \cdot 42$ & $1 \cdot 37$ & $0 \cdot 12$ & 0.03 & 0.09 \\
\hline 3 months & $6 \cdot 17$ & $1 \cdot 26$ & $6 \cdot 34$ & $1 \cdot 28$ & & & \\
\hline \multicolumn{8}{|l|}{ Fat (\% of energy) } \\
\hline Baseline & $30 \cdot 07$ & $6 \cdot 54$ & $29 \cdot 37$ & $6 \cdot 39$ & $2 \cdot 80^{(*)}$ & -0.01 & 0.01 \\
\hline 3 months & $30 \cdot 84$ & $7 \cdot 09$ & $29 \cdot 64$ & $6 \cdot 65$ & & & \\
\hline
\end{tabular}

${ }^{(*)} P<0 \cdot 10,{ }^{*} P<0 \cdot 05$

gender by condition for vitamin C. Separate analyses (data not shown) revealed a significant effect for percentage energy from fat in the overweight group $(n 132)(F=5 \cdot 75$, $P=0 \cdot 02)$. In the control group fat intake increased from $29 \cdot 6$ (SD $7 \cdot 1$ ) \% of energy to $31 \cdot 4$ (SD 9.1) \% of energy; in the intervention group fat intake decreased slightly from $28 \cdot 4$ (SD $5 \cdot 8$ ) \% of energy to $27 \cdot 4(\mathrm{SD} 7 \cdot 1$ ) \% of energy.

\section{Discussion}

The Food-O-Meter is a pilot version of a web-based tailored nutrition intervention for adolescents, developed for and implemented in six European cities. The aim of the intervention is to provide individualised advice to adolescents concerning their eating habits. Eating habits are very complex and a lot of items have to be considered when giving dietary advice, resulting in long texts or lessons. Tailored interventions can focus on the main problems of the eating habits of the respondents; the feedback given is specific for the person and can be kept shorter than general dietary advice. We hypothesised that short individualised advice would have more effect on the eating behaviour of adolescents than long standardised advice. Tailored interventions in adults showed positive effects for several dietary habits and effects were most consistent for fat reduction ${ }^{(42)}$; and also for adolescents tailored interventions on fat ${ }^{(43)}$ had positive or promising results. For the first time, a tailored intervention was developed aiming at giving advice on the total diet of adolescents.

\section{Feasibility and acceptability}

Implementation of the intervention differed between the European centres due to differences in and problems with ICT infrastructure in the schools and motivation of the teachers and the adolescents. In two study centres it was impossible to include the foreseen 200 students: in Dortmund, data on a considerable number of pupils were lost due to technical problems; in Heraklion, the implementation was problematic. Experience during the HELENA 
cross-sectional study with a computerised $24 \mathrm{~h}$ recall showed limited computer facilities in Cretan schools and a high level of computer illiteracy among the younger adolescents. The solution was to bring the adolescents and their informatics teachers to the university campus. Although successful in ensuring a high completion rate for T1, this procedure was not feasible at T2 and T3. In Stockholm, the acceptability of the intervention by the teachers was less positive; the teachers refused to give more school hours for the implementation and evaluation as the HELENA cross-sectional study already had a great impact on curriculum time. Stockholm students were asked and instructed to use the application at home or during free time at school. About half of the students started the intervention. The fact that the intervention was nested in a cross-sectional study with a lot of questionnaires might explain these results.

The evaluation of the tailored advice as well as the standardised advice was positive overall taking into account that it was the teacher who decided if the adolescents participated or not. The evaluation was more positive than found in earlier research with computerised tailored advice for fat reduction implemented in schools ${ }^{(43)}$. The more positive evaluation in the control condition of the present intervention compared with the previous fat advice might be due to the fact that the present intervention gave information on the total diet and that several topics were covered: in this way more students could find something interesting for them. In the intervention condition the overall positive evaluation might be due to the personalisation of the advice: the adolescents only got advice on problematic aspects of their personal eating habits. In addition, the computertailored advice used in the present study was much shorter than the version used in the previous study ${ }^{(43)}$. However, the score for 'the advice was too long' was rather high in the intervention condition as was the score for 'the advice did not contain enough info'. So the short tabular format did not contain the information the adolescents were expecting or needed. There were significant gender differences in the appreciation of the intervention, and more information is needed on what boys expect from such an intervention. A positive aspect was that overweight adolescents scored higher in the intervention condition on having read the advice and on the intention to use the advice. This positive evaluation was also reflected in the effect on fat intake especially in overweight adolescents.

The acceptability study revealed that adolescents are not very eager to use an intervention such as the Food-O-Meter more than once. The rate of participation dropped in all study centres during the second and third measurements. In those study centres where the teachers were willing to stimulate the adolescents to use the intervention and gave dedicated time during school hours, the participation rate was satisfactory. The feasibility study also showed that repeated use of the intervention should probably be embedded in a whole school programme. Additionally, nesting the impact study within the HELENA cross-sectional study resulted in an overload of measurements in schools, resulting in a lack of motivation to fulfil all the requirements for the intervention study, which was the last element of the HELENA activities in the schools.

\section{Nutrient intakes}

Analyses were done for the target nutrients fibre, Ca, vitamin $\mathrm{C}, \mathrm{Fe}$ and percentage energy from fat. After 1 month a modest effect of the intervention was found for fat intake. Students receiving the standardised advice increased their fat intake, while fat intake was stable in the intervention condition. On the other hand, after 3 months, when the control group received the standardised advice twice and the intervention group received the tailored advice a second time, there was only a trend for an intervention effect of the tailored advice on fat intake in the total group. However in the overweight group there was a clear significant positive effect. In this important target group, the standardised advice resulted in an increase in fat intake in the control group but a clear decrease in fat intake in the intervention group. The findings on fat intake are more positive than the results of an earlier tailored computerised fat intervention ${ }^{(43)}$. In the present study, the more favourable evaluation of the intervention might have contributed to this result. The positive result in the overweight group might be due to a higher motivation of this group to change ${ }^{(44)}$. However, it should be noted that the overweight group reported a lower fat intake at all measurements than calculated for the total group.

As for the other nutrients, there was a significant positive effect only for vitamin $\mathrm{C}$ intake in the overweight group after 1 month.

A possible explanation for the generally modest effects is the format of the tailored advice. The tailored advice was given in a short tabular format. This format gave a short overview of the intake of the adolescent at the nutrient level, the shortcomings and suggestions to enhance their eating habits when needed. However, this short format might not be easy to understand for some students. Adolescents' evaluation of the advice also indicated that the students did not receive enough information to change their behaviour. Additionally, because the intervention targeted the total diet it was not possible to include psychosocial determinants of the intake, as these determinants are different for different foods. Another explanation for the modest effects might be that not enough adolescents got advice to change their behaviour because of the overestimation of their energy, Fe, fibre and vitamin $\mathrm{C}$ intakes and the underestimation of their percentage energy from fat due to the use of an $\mathrm{FFQ}^{(36)}$. The effects of the overestimation on the generated advice should be further explored. 


\section{Strengths and limitations of the study}

Strengths of the study are the evaluation of a tailored intervention against a standardised intervention and the evaluation in several European cities under real-life conditions. However the study also has several limitations. The samples in the study are rather small, and the loss of cases due to technical problems and non-availability of computers affects the reliability of the results. Numbers within cities were too small to execute separate cityspecific analyses. Future research should confirm the intervention effects in larger samples. The effects are based on self-reported intake of the adolescents. Although validated questionnaires were used, self-reported data are more often biased by social desirability and inaccurate responses.

\section{Recommendations}

To enhance the reliability of the tailored advice, the FFQ should be validated for each participating country and adapted where needed.

To enhance the effectiveness of the intervention, more research is needed on motivations of adolescents for changing their eating behaviour and what information they need to realise intentions for change. With this information the feedback can be made more relevant for the adolescents. The computer-based intervention in the present study was implemented as a stand-alone intervention, but more information is needed on what are the best conditions to implement the intervention, and the context of the implementation might be different in different countries depending on the nutrition education and nutrition policy in schools. A short motivational lesson before the start of the intervention and a follow-up in the classroom on what the adolescents did with the advice might enhance the effectiveness. Larger country samples are also needed to power the study to detect small but relevant intervention effects.

\section{Conclusions}

The current pilot study showed that, in most but not all study centres, the implementation of a web-based tailored intervention was feasible and although generally well appreciated by the adolescents, the advice did not contain the expected or needed information for the behaviour change. However, the ICT infrastructure in the schools can hinder the implementation, and in some cases the teachers should be better supported to motivate the adolescents to complete the intervention. The results were modest but clear for percentage energy from fat, specifically in the overweight group. Several aspects should be studied further to enhance the effectiveness of the intervention and larger studies should be conducted to test the effect on the total diet of all adolescents or subgroups of adolescents.

\section{Acknowledgements}

The HELENA Study takes place with financial support from the European Community Sixth RTD Framework Programme (Contract FOOD-CT-2005-007034). The content of the present paper reflects the author's views only and the European Community is not liable for any use that may be made of the information contained herein. There are no conflicts of interest. L.M., I.D.B.; L.A.M. and C.V. were responsible for the design of the study; L.M., T.L.C., C.V., C.O., C.M., M.K., A.P., Y.M., S.D., L.H. and I.D.B. developed the intervention and were responsible for the implementation; C.V. did the statistical analysis; L.M. drafted the article. All authors read the drafts of the paper, commented on them and approved the final version.

\section{References}

1. Story M, Neumark-Sztainer D \& French S (2002) Individual and environmental influences on adolescent eating behaviors. J Am Diet Assoc 102, 3 Suppl., S40-S51.

2. Lytle L \& Kubik M (2003) Nutritional issues for adolescents. Best Pract Res Clin Endocrinol Metab 17, 177-189.

3. Cruz J (2000) Dietary habits and nutritional status in adolescents over Europe - Southern Europe. Eur J Clin Nutr 54, Suppl., 1, S29-S35.

4. Currie C, Roberts C, Morgan A et al. (2004) Young People's Health in Context. Health Behaviour in School-aged Children (HBSC) Study: International Report from the 2001/2002 Survey. Copenhagen: WHO Regional Office for Europe.

5. Lambert J, Agostoni C, Elmadfa I et al. (2004) Dietary intake and nutritional status of children and adolescents in Europe. Br J Nutr 92, Suppl. 2, S147-S211.

6. Yngve A, Wolf A, Poortvliet E et al. (2005) Fruit and vegetable intake in a sample of 11 -year-old children in 9 European countries: the Pro Children cross-sectional survey. Ann Nutr Metab 49, 236-245.

7. Centers for Disease Control and Prevention (1997) Guidelines for school health programs to promote lifelong healthy eating. $J$ Sch Health 67, 9-26.

8. Kelder SH, Perry CL, Klepp KI et al. (1994) Longitudinal tracking of adolescent smoking, physical activity, and food choice behaviors. Am J Public Health 84, 1121-1126.

9. Lien N, Lytle L \& Klepp K-I (2001) Stability in consumption of fruit, vegetables and sugary food in a cohort from age 14 to age 21. Prev Med 33, 217-226.

10. Maynard M, Gunnell D, Emmett P et al. (2003) Fruit, vegetables, and antioxidants in childhood and risk of adult cancer: the Boyd Orr cohort. J Epidemiol Community Health 57, 218-225.

11. Food and Agriculture Organization of the United Nations/ World Health Organization (2004) Fruit and Vegetables for Health: Report of a Joint FAO/WHO Workshop, 1-3 September 2004, Kobe, Japan. Geneva: WHO.

12. Blanchette L \& Brug J (2005) Determinants of fruit and vegetable consumption among 6-12-year-old children and effective interventions to increase consumption. J Hum Nutr Diet 18, 431-443.

13. Kubik M, Lytle L, Hannan P et al. (2003) The association of the school food environment with dietary behaviors of young adolescents. Am J Public Health 93, 1168-1173.

14. Wechsler H, Devereaux R, Davis M et al. (2000) Using the school environment to promote physical activity and healthy eating. Prev Med 31, issue 2, S121-S237. 
15. Walter HJ \& Wynder EL (1989) The development, implementation, evaluation, and future directions of a chronic disease prevention program for children: the 'Know Your Body' studies. Prev Med 18, 59-71.

16. Manios Y \& Kafatos A (1999) Health and nutrition education in elementary schools: changes in health knowledge, nutrient intakes and physical activity over a six year period. Public Health Nutr 2, 445-448.

17. Gortmaker S, Peterson K, Wiecha J et al. (1999) Reducing obesity via a school-based interdisciplinary intervention among youth: Planet Health. Arch Pediatr Adolesc Med 153, 409-418.

18. French S, Story M, Fulkerson J et al. (2004) An environmental intervention to promote lower-fat food choices in secondary schools: outcomes of the Tacos study. Am J Public Health 94, 1507-1512.

19. Sallis JF, McKenzie TL, Conway TL et al. (2003) Environmental interventions for eating and physical activity: a randomized controlled trial in middle schools. Am J Prev Med 24, 209-217.

20. Kroeze W, Werkman A \& Brug J (2006) A systematic review of randomized trials on the effectiveness of computertailored education on physical activity and dietary behaviors. Ann Behav Med 31, 205-223.

21. de Vries H \& Brug J (1999) Computer-tailored interventions motivating people to adopt health promoting behaviours: introduction to a new approach. Patient Educ Couns 36, 99-105.

22. Kreuter MW, Strecher VJ \& Glassman B (1999) One size does not fit all: the case for tailoring print materials. Ann Behav Med 21, 276-283.

23. Brug J, Oenema A \& Campbell M (2003) Past, present, and future of computer-tailored nutrition education. Am J Clin Nutr 77, 4 Suppl., 1028S-1034S.

24. Brug J, Oenema A, Kroeze W et al. (2005) The internet and nutrition education: challenges and opportunities. Eur J Clin Nutr 59, Suppl. 1, S130-S137.

25. Haerens L, Deforche B, Maes L et al. (2006) Evaluation of a 2 -year physical activity and healthy eating intervention in middle school children. Health Educ Res 21, 911-921.

26. Frenn M, Malin S, Brown RL et al. (2005) Changing the tide: an Internet/video exercise and low-fat diet intervention with middle-school students. Appl Nurs Res 18, 13-21.

27. Casazza K \& Ciccazzo M (2007) The method of delivery of nutrition and physical activity information may play a role in eliciting behavior changes in adolescents. Eat Behav 8, 73-82.

28. Nigg CR, Allegrante JP \& Ory M (2002) Theory-comparison and multiple-behavior research: common themes advancing health behavior research. Health Educ Res 17, 670-679.

29. Schuit AJ, van Loon AJ, Tijhuis M et al. (2002) Clustering of lifestyle risk factors in a general adult population. Prev Med 35, 219-224.

30. Moreno LA, Gonzalez-Gross M, Kersting M et al. (2008) Assessing, understanding and modifying nutritional status, eating habits and physical activity in European adolescents: the HELENA (Healthy Lifestyle in Europe by Nutrition in Adolescence) Study. Public Health Nutr 11, 288-299.

31. De Henauw S, Gottrand F, De Bourdeaudhuij I et al. (2007) Nutritional status and lifestyle of adolescents in a public health perspective. The HELENA Project - Healthy Lifestyle in Europe by Nutrition in Adolescence. Public Health 15, 187-197.

32. De Bourdeaudhuij I, Maes L, De Henauw S et al. (2010) Evaluation of a computer tailored physical activity intervention in adolescents in 6 European countries: the Activ-O-Meter in the Helena Intervention Study. J Adolesc Health 46, 458-466.

33. Brug J, Campbell M \& van Assema P (1999) The application and impact of computer-generated personalized nutrition education: a review of the literature. Patient Educ Couns 36, 145-156
34. Vandelanotte C, Matthys C \& De Bourdeaudhuij I (2004) Reliability of a computerized questionnaire to measure fat intake in Belgium. Nutr Res 24, 621-631.

35. Maes L, Vereecken CA, Gedrich K et al. (2008) A feasibility study of using a diet optimization approach in a web based computer tailoring intervention for adolescents. Int J Obes (Lond) 32, Suppl. 5, S76-S81.

36. Vereecken CA, De Bourdeaudhuij I, Maes L et al. (2010) The HELENA online food frequency questionnaire: reproducibility and comparison with four 24-h recalls in BelgianFlemish adolescents. Eur J Clin Nutr 64, 541-548.

37. von Gernot H, Klemm C, Cornelius S et al. (1998) The Federal Food Code and Nutrient Data Base (BLS II.2) Conception, Structure and Documentation of the Data Base blsdat. Berlin: BgVV.

38. NEVO (2001) Dutch Food Composition Table. Den Haag: Stichting NEVO.

39. Nubel (2004) Belgian Food Composition Table. Brussels: Ministry of Public Health.

40. Vandelanotte C \& De Bourdeaudhuij I (2003) Acceptability and feasibility of a computer-tailored physical activity intervention using stages of change: project FAITH. Health Educ Res 18, 304-317.

41. Moreno LA, De Henauw S, Gonzáles-Gross M et al. (2008) Design and implementation of the Healthy Lifestyle in Europe by Nutrition in Adolescence Cross-Sectional Study. Int J Obes (Lond) 32, Suppl. 5, S4-S11.

42. Kroeze W, Werkman A \& Brug J (2006) A systematic review of randomized trials on the effectiveness of computertailored education on physical activity and dietary behaviors. Ann Behav Med 31, 205-223.

43. Haerens L, Deforche B, Maes L et al. (2003) A computertailored fat intake intervention among adolescents: results of a randomized controlled trial. Ann Behav Med 34, 253-262.

44. Brug J, Campbell M \& van Assema P (1999) The application and impact of computer-generated personalized nutrition education: a review of the literature. Patient Educ Couns 36, 145-156.

\section{Appendix}

\section{HELENA Study Group}

Co-ordinator: Luis A. Moreno.

Core Group members: Luis A. Moreno, Fréderic Gottrand, Stefaan De Henauw, Marcela González-Gross, Chantal Gilbert.

Steering Committee: Anthony Kafatos (President), Luis A. Moreno, Christian Libersa, Stefaan De Henauw, Jackie Sánchez, Fréderic Gottrand, Mathilde Kersting, Michael Sjöstrom, Dénes Molnár, Marcela González-Gross, Jean Dallongeville, Chantal Gilbert, Gunnar Hall, Lea Maes, Luca Scalfi.

\section{Project Manager: Pilar Meléndez.}

Universidad de Zaragoza (Spain): Luis A. Moreno, Jesús Fleta, José A. Casajús, Gerardo Rodríguez, Concepción Tomás, María I. Mesana, Germán Vicente-Rodríguez, Adoración Villarroya, Carlos M. Gil, Ignacio Ara, Juan Revenga, Carmen Lachen, Juan Fernández Alvira, Gloria Bueno, Aurora Lázaro, Olga Bueno, Juan F. León, Jesús $\mathrm{M}^{a}$ Garagorri, Manuel Bueno, Juan Pablo Rey López, Iris Iglesia, Paula Velasco, Silvia Bel. 
Consejo Superior de Investigaciones Cientificas (Spain): Ascensión Marcos, Julia Wärnberg, Esther Nova, Sonia Gómez, Esperanza Ligia Díaz, Javier Romeo, Ana Veses, Mari Angeles Puertollano, Belén Zapatera, Tamara Pozo.

Université de Lille 2 (France): Laurent Beghin, Christian Libersa, Frédéric Gottrand, Catalina Iliescu, Juliana Von Berlepsch.

Research Institute of Child Nutrition Dortmund, Rheinische Friedrich-Wilhelms-Universität Bonn (Germany): Mathilde Kersting, Wolfgang Sichert-Hellert, Ellen Koeppen.

Pécsi Tudományegyetem (University of Pécs) (Hungary): Dénes Molnar, Eva Erhardt, Katalin Csernus, Katalin Török, Szilvia Bokor, Mrs Angster, Enikö Nagy, Orsolya Kovács, Judit Répasi.

University of Crete School of Medicine (Greece): Anthony Kafatos, Caroline Codrington, María Plada, Angeliki Papadaki, Katerina Sarri, Anna Viskadourou, Christos Hatzis, Michael Kiriakakis, George Tsibinos, Constantine Vardavas Manolis Sbokos, Eva Protoyeraki, Maria Fasoulaki.

Institut für Ernährungs- und Lebensmittelwissenschaften - Ernährungphysiologie, Rheinische Friedrich Wilhelms Universität (Germany): Peter Stehle, Klaus Pietrzik, Marcela González-Gross, Christina Breidenassel, Andre Spinneker, Jasmin Al-Tahan, Miriam Segoviano, Anke Berchtold, Christine Bierschbach, Erika Blatzheim, Adelheid Schuch, Petra Pickert.

University of Granada (Spain): Manuel J. Castillo Garzón, Ángel Gutiérrez Sáinz, Francisco B. Ortega Porcel, Jonatan Ruiz Ruiz, Enrique García Artero, Vanesa España Romero, David Jiménez Pavón, Cristóbal Sánchez Muñoz, Victor Soto, Palma Chillón, Jose M. Heredia, Virginia Aparicio, Pedro Baena, Claudia M. Cardia, Ana Carbonell.

Istituto Nazionalen di Ricerca per gli Alimenti e la Nutrizione (Italy): Davide Arcella, Giovina Catasta, Laura Censi, Donatella Ciarapica, Marika Ferrari, Cinzia Le Donne, Catherine Leclerq, Luciana Magrì, Giuseppe Maiani, Rafaela Piccinelli, Angela Polito, Raffaela Spada, Elisabetta Toti.

University of Napoli 'Federico II' Department of Food Science (Italy): Luca Scalfi, Paola Vitaglione, Concetta Montagnese.

Ghent University (Belgium): Ilse De Bourdeaudhuij, Stefaan De Henauw, Tineke De Vriendt, Lea Maes, Christophe Matthys, Carine Vereecken, Mieke de Maeyer, Charlene Ottevaere, Inge Huybrechts.

Medical University of Vienna (Austria): Kurt Widhalm, Katharina Phillipp, Sabine Dietrich, Birgit Kubelka, Marion Boriss-Riedl.
Harokopio University (Greece): Yannis Manios, Eva Grammatikaki, Zoi Bouloubasi, Tina Louisa Cook, Sofia Eleutheriou, Orsalia Consta, George Moschonis, Ioanna Katsaroli, George Kraniou, Stalo Papoutsou, Despoina Keke, Ioanna Petraki, Elena Bellou, Sofia Tanagra, Kostalenia Kallianoti, Dionysia Argyropoulou, Katerina Kondaki, Stamatoula Tsikrika, Christos Karaiskos.

Institut Pasteur de Lille (France): Jean Dallongeville, Aline Meirhaeghe.

Karolinska Institutet (Sweden): Michael Sjöstrom, Patrick Bergman, María Hagströmer, Lena Hallström, Mårten Hallberg, Eric Poortvliet, Julia Wärnberg, Nico Rizzo, Linda Beckman, Anita Hurtig Wennlöf, Emma Patterson, Lydia Kwak, Lars Cernerud, Per Tillgren, Stefaan Sörensen.

Asociación de Investigación de la Industria Agroalimentaria (Spain): Jackie Sánchez-Molero, Elena Picó, Maite Navarro, Blanca Viadel, José Enrique Carreres, Gema Merino, Rosa Sanjuán, María Lorente, María José Sánchez, Sara Castelló.

Campden BRI (UK): Chantal Gilbert, Sarah Thomas, Elaine Allchurch, Peter Burguess.

SIK - Institutet foer Livsmedel och Bioteknik (Sweden): Gunnar Hall, Annika Astrom, Anna Sverkén, Agneta Broberg.

Meurice Recherche \& Development asbl (Belgium): Annick Masson, Claire Lehoux, Pascal Brabant, Philippe Pate, Laurence Fontaine.

Campden \& Chorleywood Food Development Institute (Hungary): Andras Sebok, Tunde Kuti, Adrienn Hegyi.

Productos Aditivos SA (Spain): Cristina Maldonado, Ana Llorente.

Cárnicas Serrano SL (Spain): Emilio García.

Cederroth International AB (Sweden): Holger von Fircks, Marianne Lilja Hallberg, Maria Messerer.

Lantmännen Food RED (Sweden): Mats Larsson, Helena Fredriksson, Viola Adamsson, Ingmar Börjesson.

European Food Information Council (Belgium): Laura Fernández, Laura Smillie, Josephine Wills.

Universidad Politécnica de Madrid (Spain): Marcela González-Gross, Agustín Meléndez, Pedro J. Benito, Javier Calderón, David Jiménez-Pavón, Jara Valtueña, Paloma Navarro, Alejandro Urzanqui, Ulrike Albers, Raquel Pedrero, Juan José Gómez Lorente. 